\title{
A INFLUÊNCIA DA INTERNET NOS ADOLESCENTES COM AÇÕES SUICIDAS
} THE INFLUENCE OF THE INTERNET ON ADOLESCENTS WITH SUICIDAL ACTIONS

\author{
Thales de Oliveira Abreu', Marjane Bernardy Souza²
}

RECEBIDO EM: 15/02/2017 / ACEITO EM: 10/04/2017

DOI: $10.5902 / 2317175825868$

\section{RESUMO}

Este estudo investiga a relação da internet e do contingente de informações sobre ideações suicidas com os adolescentes. Para isso, foi realizada uma revisão sistemática de bibliografias sobre a temática abordada na base de dados Biblioteca Virtual da Saúde (BVS), procedendo-se à coleta, categorização, avaliação, interpretação e síntese dos dados. Foram encontrados dois artigos - "Agressão entre pares no espaço virtual: definições, impactos e desafios do cyberbullying", que aborda a problemática do cyberbullying entre os adolescentes vitimados e as consequências sociais e psicológicas desse fenômeno, e "Análise do conteúdo de sites que abordam o suicídio", que analisa sites que discutem a temática suicídio, sob a investigação de seus conteúdos. Nos dois artigos, verificou-se a inferência ao tema suicídio em adolescentes vulneráveis conectados virtualmente, bem como a facilidade para acessar esse conteúdo em sites. Concluiu-se que os conteúdos disponíveis on-line chegam de maneira rápida e eficiente para o adolescente com ideação suicida, servindo de informativo no que diz respeito às práticas suicidas propriamente ditas ou promovendo a vida.

Palavras-chaves: adolescentes; ideação suicida; internet.

\footnotetext{
1 Graduando em Psicologia (ULBRA).

2 Possui graduacão em Psicologia-Bachalerado pela Universidade do Vale do Rio dos Sinos (UNISINOS-1991) e em Psicologia-Licenciatura pela Universidade Federal do Rio Grande do Sul (UFRGS-1994), especialização em Aconselhamento das Relações Familiares pela Pontifícia Universidade Católica do Rio Grande do Sul (PUCRS-1997) e mestrado em Família e Sistemas Sociais pelo Instituto Superior Miguel Torga - Coimbra -Portugal (ISMT-2004).
} 


\begin{abstract}
This study investigates the relation between the internet and the contingent of information about suicidal ideation with teenagers. A systematic review of bibliographies about the selected theme in the database Biblioteca Virtual da Saúde (BVS) has been made. Data were collected and the categorization of the studies was made, subsequently, the data were evaluated, interpreted and synthesized. Two articles were found: "Peers aggression in the virtual space: definitions, impacts, and challenges of cyberbullying", approaches the issue of cyberbullying among victimized adolescents and the social and psychological consequences presented in this public; and "Content analysis of websites discussing suicide", analyzing the sites that approach the subject of suicide, under the investigation of its contents. In both articles, was verified the reference to the subject suicide in vulnerable adolescents connected virtually as well as the facility in accessing this content in websites. The available online content comes quickly and efficiently to the adolescent with suicidal ideation, serving as information about the suicidal practices or promoting life.
\end{abstract}

Keywords: Adolescents. Suicidal ideation. Internet.

\title{
1 Introdução
}

O adolescente, ao longo dos anos, segue ocupando uma posição vista como sinônimo de rebeldia, mudanças profundas, exageros e carências nos diversos aspectos da vida: em casa com a família, na escola, com os amigos e em outros círculos de convívio. Quando se torna adolescente, o sujeito se vê frente a um corpo de criança que está se transformando lenta e estranhamente, assim como a uma mente que já anseia por outras coisas que não mais a proteção do seio de sua família, como os brinquedos e tudo que envolve o mundo infantil. Nesse momento, algumas questões surgem e tomam uma proporção anárquica que, vista de fora, pode parecer mera rebeldia, inconformismo, birra ou oposição a regras e leis; entretanto, é preciso destacar a combustão biológica e psíquica que esse corpo em transformação carrega.

Uma relação entre o sentido da vida e a identidade é estabelecida por Bronk (2011) e sustentada por Rodriguez e Damásio (apud HABIZANG et al., 2014) quando afirmam que o momento em que o adolescente começa a ter definida a sua percepção de autoconceito, autoestima e autoeficácia e tende a conduzir a sua vida de forma coerente é um processo interrelacional e concomitante. É nesse momento que o sujeito se agarra a um motivo importante ao seu julgamento e ali empenha sua energia, resolvendo paralelamente sua suposta crise de identidade. Ao encontrar um propósito de vida, o adolescente empenhado consegue responder de forma cada vez melhor questões existenciais como "quem sou?" e "para que estou no mundo?".

Nesse período confuso em que perguntas são feitas e uma ebulição psicológica acontece, o adolescente, quando não encontra suas respostas de forma sadia ou nem sequer chega a encontrá-las, pode voltar-se para uma 
A INFLUÊNCIA DA INTERNET NOS ADOLESCENTES COM AÇÕES SUICIDAS

conduta suicida. Entre os adolescentes que experimentam essa modalidade de exposições a riscos, de acordo com Bronk (2011) e Rodriguez e Damásio (apud HABIZANG et al., 2014), prevalecem os comportamentos suicidas nos grupos com idade mais avançada, entre 18 e 19 anos, do sexo feminino; as mulheres estão mais intimamente ligadas a questões de ordem afetiva e relação familiar, sendo, dessa forma, mais propensas às internalizações.

Pela relevância do tema na atualidade, em que a disseminação das mídias sociais se mostra aliada ao uso inadequado e sem moderação de tais mídias pelos jovens, principalmente em casos de ideação suicida, a presente pesquisa aborda a necessidade de um olhar mais crítico para essas questões. Com base nos dados da Organização Mundial de Saúde (OMS, 2014), que evidenciam que uma pessoa comete suicídio a cada 40 segundos e que, de 2002 a 2012, houve um crescimento na taxa de suicídio entre crianças e pré-adolescentes com idade entre dez e 14 anos e 15 e 19 anos de $40 \%$ e 33,5\%, respectivamente, o presente trabalho de pesquisa surge a partir da preocupação com os jovens e adolescentes, que, em sua grande maioria, são os primeiros a se tornarem adeptos das atualizações tecnológicas, justamente por estarem em constante contato com a internet e por serem sempre os pioneiros em aventurar-se em todo tipo de novidade na busca de novas formas de comunicação.

Nesse sentido, com poucos estudos publicados e conteúdos informativos acerca do tema que atingem a população, surge a necessidade de uma revisão mais aprofundada do que tem sido produzido nos últimos tempos sobre adolescentes com ações suicidas que buscam orientação nas mídias sociais na internet. Sendo assim, o que se objetiva no presente artigo é investigar a contribuição da internet na ideação suicida de adolescentes.

\section{Desenvolvimento}

O Estatuto da Criança e do Adolescente (ECA, 2014) define, em seu artigo $2^{\circ}$, parágrafo único, que adolescente é a pessoa entre 12 e 18 anos, sendo prevista em lei a excepcionalidade às pessoas de 18 a 21 anos e compreendendo o período descrito como um momento primordial, em que a criança deixa de o ser, para se apropriar de seus aspectos de personalidade e vivências no meio biopsicossocial. Nas entrelinhas desse processo, Aberastury et al. (1990) destaca um fenômeno que chama de luto pela infância. Luto pelo corpo infantil que se foi, pelo papel que desempenhava na identidade infantil e pelo papel desempenhado pelos pais na infância, os quais insistem em regrar e reter esse filho ainda tido como criança, mas que está se tornando um adulto e trazendo com ele a carga da independência e do consequente envelhecimento desses pais.

Uma vez que os pais se tornam ambivalentes em aceitar esse processo e por vezes acabam sendo disfuncionais ao lado de seus adolescentes, um jogo de liberdade e prisão ocorre. As regras antes aceitas ainda que de forma 
relutante na infância figuram completamente ofensivas e inaceitáveis na adolescência. São impostos deveres, horários, vocações e maneiras corretas de comportamento, um cerco que o adolescente não tolera, instaurando uma fase em que a família e os pais passam a representar algo diferente do que vinham representando até então (ABERASTURY; KNOBEL, 1992).

Para esses autores, o período da adolescência ocorre em condições especiais, indicando uma transição da puberdade para o estado adulto, em diferentes sociedades e períodos, embora todos signifiquem o abandono de uma autoimagem. Esse desprendimento é norteado por questões de ordem externa peculiares a cada ambiente, sendo isso que torna a transição mais fácil ou mais tumultuosa. Além das manifestações como busca de si e da identidade, necessidade de fantasiar, deslocalização temporal e evolução sexual manifesta, ocorre uma necessidade de externar figurada em atitude social reivindicatória, contradições sucessivas, separação progressiva dos pais e constantes manifestações de diferentes estados de humor e ânimo. Em um contingente de diferencial entre culturas e ambientes, o conceito de normalidade acaba tomando tons diferentes.

A tendência atual sobre o processo de adolescer não considera mais a obrigatoriedade de que necessariamente se viva uma crise nessa fase, de modo que seja um período crítico. Em um primeiro momento, era vista apenas a ação biológica e naturalista da adolescência, deixando em segundo plano a ação da inserção histórica e das condições objetivas de vida, o que hoje é entendido como extremamente relevante para formar as particularidades de cada sujeito. O adolescente é, em si, a caracterização de sua cultura, de forma que os conceitos adquiridos estão ligadas ao ambiente e às maneiras como ele contextualiza o mundo e a si mesmo (SANTOS; NETO; KOLLER apud HABIZANG et al., 2014).

Atualmente, a síndrome da adolescência normal mencionada por Knobel e Aberastury (1992), ambos pioneiros em pesquisas no assunto, passa por significativas mudanças oriundas do fato de que a própria família vivenciar importantes transições, como, por exemplo: a simbolização de referenciais, a própria autoridade paterna, a erotização da criança por meio do uso de mídias que facilitam e não limitam o acesso a determinadas informações e conteúdos destinados a adultos. Essa afirmação advém da revisão feita por Viola e Vorcaro (2015), que procuraram compreender a complexidade dessa transição, e da relativização do período de latência já mencionado por Freud e que antecedente a adolescência. A incessante oferta de objetos que saciem o desejo do adolescente torna as relações intra e extrafamiliares mais voláteis, rápidas e muitas vezes descartáveis, o que fragiliza o entendimento do que é se fazer adolescente em termos de construção social e psicossexual.

No processo decorrente do adolescer, segundo Barkeley (2016), ocorrem transformações significativas no que diz respeito ao senso de pertencimento e desenvolvimento da independência. $\mathrm{O}$ adolescente apresenta uma necessidade bastante específica de desprendimento de seus pais rumo à sobrevivência 
A INFLUÊNCIA DA INTERNET NOS ADOLESCENTES COM AÇÕES SUICIDAS

no mundo adulto de uma forma funcional. É nessa busca de identidade que surgem os primeiros conflitos e divergências em relação às opiniões de seus pais e cuidadores, uma necessidade de se mostrar forte e capaz de continuar com suas próprias ideologias que leva a um afastamento da família por parte desse adolescente quando atinge entre 12 e 14 anos.

Existe, assim, um afastamento significativo no que se denomina "horizonte" de tempo mental entre os adolescentes e seus pais (BARKELEY, 2016b), uma vez que aqueles vivem fortemente focados no tempo presente e poucas vezes pensam no futuro. $O$ adolescente pensa no futuro considerando um tempo muito mais curto que seus pais, de modo que suas projeções se limitam a dias ou a meses. É nesse momento que os pais se frustram com seus filhos, evidenciando o despreparo em encarar essa nova fase do adolescente que têm em casa; sem o aval dos pais quanto a suas ideias e ações, buscam naturalmente amigos com quem compartilhar e validar seus princípios. Todo o senso de participação em comunidade e desenvolvimento no mundo social adulto ocorre na adolescência por meio desses amigos.

Uma vez que a autoimagem está se constituindo, os lutos estão acontecendo, o estado emocional está instável e toda a carga hormonal e biológica está em ebulição, a experimentação de várias situações e personalidades segue, muitas vezes, um curso desenfreado no que concerne à liberdade. Existe, ainda que às vezes implícita, uma cobrança em pertencer a grupos e provar competências aos grupos de amigos, dando vazão às condutas de risco e a comportamentos abusivos, principalmente com álcool, drogas, comportamentos sexuais de risco, comportamentos antissociais e comportamento suicida. No trabalho de Zappe e Dell'Aglio (2016), a temática é abordada compreendendo todos esses comportamentos de risco associados principalmente ao convívio com familiares com esses mesmos estilos de vida, a condutas de amigos próximos e a eventos estressores, como desemprego na família e violência extra ou intrafamiliar.

Quanto mais o adolescente avança na sua idade, menos supervisão dos pais ele possui e, consequentemente, quanto mais mantém contato com esse tipo de prática, maior é o risco (ZAPPE E DELL'AGLIO, 2016b). Embora seja a morte ou a intenção de morrer algo temido, o adolescente pode entender como alternativa para a solução de seus conflitos atentar contra a própria vida, sendo esse fenômeno um misto de diversas modificações biológicas, psicológicas e sociais.

De acordo com os pioneiros na pesquisa sobre suicídio, Werlang, Borges e Fensterseifer (2005), todo ato no qual a pessoa atenta contra si mesma, independentemente da gravidade com que o faz, é considerado uma ação suicida, que pode ser dos seguintes tipos: ideação suicida, tentativa de suicídio e suicídio consumado, sendo estas ações que esquematizam, respectivamente, a ideia do sujeito suicidar-se, a ação sem sucesso e a tentativa fatal.

Pensamentos suicidas podem até ser parte de um processo tumultuoso de lidar com conflitos, dúvidas e ambivalências da adolescência; entretanto, o 
que torna a situação disfuncional é a intensidade e a recorrência com que esse pensamento se faz presente como única saída desses conflitos. Nesse sentido, as situações em que o adolescente recorre a essa ideia ou a dificuldade em se desfazer dela são fatores decisivos para a distinção entre adolescentes com condições de gerir conflito e aqueles prestes a cometer suicídio (BASTOS; MOREIRA 2015).

O suicídio em adolescentes é pouco estudado, uma vez que os dados quantitativos acabam se perdendo e as informações acabam sendo modificadas por ocultação de familiares ou até mesmo sendo vistas como causadas por "causas externas", o que em termos quantitativos dificulta a obtenção de dados corretos, tornando deficitária a fidelidade de qualquer pesquisa do tipo (BORGES; WERLANG, 2006). Diante disso, fatores de ordem psicológica, biológica e socioeconômica são fundamentais para a questão qualitativa da pesquisa. A própria ideação suicida já se caracteriza como um risco efetivo e, aliada à desesperança e à depressão, não deve ser vista como menos importante. As atitudes que muitas vezes buscam demonstrar, na forma de confronto, arrogância, força e poder, na realidade escondem em si um pedido de atenção, de carinho, de limite e de proteção, como afirmam Bastos e Moreira (2015) embasados nas pesquisas de Borges (2005).

Em termos avaliativos, o suicídio não se caracteriza como estático, conforme prevê Botega (2015), ou seja, não pode ser mantido em um diagnóstico sem mudanças. No momento em que o risco é avaliado como crônico devido às ideações, pode tornar-se agudo, transformando-se em uma crise emergencial, o que exige avaliações sistemáticas. No entanto, é possível observar os indícios físicos e comportamentais do adolescente em risco de suicídio, tais como ansiedade, desassossego e insônia. A agitação motora que antecede a crise, as preocupações em excesso e os sintomas corporais são o que levam ao desespero, evidenciado, em termos de objetivos clínicos e terapêuticos, a necessidade de controle dessa ansiedade e das crises fóbicas (pânico).

Outro ponto relevante a ser observado consiste no isolamento, clássico modo de expressão de um estado emocional de depressão, o que se torna difícil de ser diferenciado das condutas recorrentes de busca por privacidade na adolescência. Porém, é preciso ter um olhar mais crítico em relação a isso, tendo em vista que esse desejo intenso de ficar sozinho pode estar diretamente ligado a transtornos de humor e à perda do interesse no convívio social. É exatamente nesses momentos solitários e potencialmente propensos a pensamentos suicidas recorrentes que o adolescente consegue o tempo e o espaço para pensar em sua morte e também arquitetá-la, utilizando-se, para isso, das mais diversas formas. A intenção de se matar é intensificada por dois fatores antagônicos: a intensidade da motivação e o grau com que esse sentimento está em conflito com o desejo de permanecer vivendo (BOTEGA, 2015). Para Botega (2015b), a existência de um plano tira o paciente do grau 1 em termos de gravidade, sendo visto como moderado ou alto o risco de suicídio nesses casos. Segundo o autor, 6.483 adolescentes norte-americanos 
A INFLUÊNCIA DA INTERNET NOS ADOLESCENTES COM AÇÕES SUICIDAS

com faixa etária entre 13 e 18 anos foram avaliados em um período de cinco anos, e, ao fim do tempo estimado, mais de $60 \%$ deles já tinham um plano concreto de como se matar ou já haviam tentado o suicídio, em contrapartida com os outros $20 \%$ que tentaram suicídio sem haver mencionado ter um plano.

Em seu convívio social, o adolescente pode dispor de uma gama de ferramentas para alimentar seu estado de sofrimento psíquico, seja por pensamentos ruminantes, seja pelo contato com pessoas via mídias sociais ou celulares. É por meio dessas mesmas mídias que os adolescentes podem sofrer com ameaças sem rosto, como o cyberbulling, o assédio ou a exposição a outros tipos de conteúdo ameaçadores ou impróprios (RICH, 2013b apud ABREU; EISENSTEIN; ESTEFENON, 2014). Diante disso, estudos feitos por Ryu et al. (2010) voltaram-se para a relação entre dependência da internet e depressão e suicídio em países asiáticos e norte-americanos. Na China, dos 3.507 estudantes adolescentes investigados, 5,2\% demonstraram dependência severa da internet e, destes, 27,4\% possuíam ideação suicida, 9,5\% tinham o plano arquitetado e $2,6 \%$ fizeram a tentativa.

Atualmente, existem as chamadas "redes sociais digitais", definidas por Santaella (2003) como um tipo de mídia mais específica de comunicação em massa, em que há uma constante troca de informações advindas de uma emergência cultural mundial (VERMELHO et al., 2014). Nesse contexto, as tecnologias de informações do mundo contemporâneo, como computadores, acesso à internet e uso de celulares, revolucionaram a forma como as pessoas se comunicam, socializam, buscam e trocam informações. Assim, informações sobre os mais variados temas estão disponíveis com um simples clique ou toque de tela (UNGERER, 2013 apud ABREU; EISENSTEIN; ESTEFENON, 2014).

Não há como evitar as mídias que se mostram cada vez mais poderosas e essenciais. Sem implicar benefícios nem malefícios, acabam sendo prejudiciais no momento em que são usadas de uma forma que reestrutura a realidade de quem usa tal ferramenta de maneira onipresente, baseando nela suas decisões. Por conta desse movimento, mudou-se a forma de trabalhar e de coexistir, principalmente entre os jovens, que se tornam multitarefados e expostos, em tempos cada vez maiores por dia, nas redes. Desde criança, aprende-se a navegar e usar as mídias, muito mais rapidamente do que um adulto o faria (RICH, 2013 apud ABREU; EISENSTEIN; ESTEFENON, 2014).

No contexto histórico dos movimentos sociais, a comunicação em massa passou por uma importante transformação, que Castells (2012) denomina tecnológica e organizacional. A autocomunicação tem base em comunicações multidirecionalizadas e interativas na internet, sendo agravada pelas redes de comunicação sem fio, as quais potencializam a comunicação por toda a parte e constituem uma das principais características da estruturação social moderna. O autor afirma, ainda, que, por ser uma rede de muitas redes, a conexão em massa possui uma característica própria e que, mesmo não possuindo uma fonte integradora identificada, a internet ocupa uma função de coordenação 
e deliberação por causa da inter-relação entre múltiplos núcleos. Sendo assim, os adolescentes não precisam de uma liderança identificada, um centro de controle ou uma organização verticalizada para passar informações, o que aumenta a chance de participação no movimento devido a essa abertura e ausência de fronteiras definidas.

Seguindo a análise do fenômeno, é possível perceber, como descreve Castells (2012b), que as redes estabelecidas pela internet constituem um senso de companheirismo, em que pessoas superam seus medos. Esse companheirismo não é o grupo em si, uma vez que, para isso, são necessários objetivos e valores em comum de modo geral, mas o "espírito" que se forma no fenômeno ainda que cada indivíduo ingresse com objetivos e motivações próprias, descobrindo, a partir disso, seus denominadores comuns na prática desse movimento. Dessa maneira, o direcionamento contínuo é o início dessa fonte de poder do coletivo.

Os adolescentes, à medida que conquistam sua autonomia e estabelecem uma identidade no mundo adulto, consideram como importantes para a constituição de si roupas e acessórios que vêm com o peso de uma marca, de um cosmético, de um eletrônico, de uma celebridade da música ou do cinema em que se espelhar, e o mundo digital oferece um leque de escolhas e um ambiente seguro, em que minorias raciais, sexuais e étnicas encontram semelhantes e alento para suas angústias. Por outro lado, o que se evidencia é um risco bastante elevado de esse grupo se envolver com abuso de substâncias, depressão e suicídio. Mídias sociais tornam os relacionamentos bastante íntimos em um tempo muito curto, de forma que a dimensão de amizade figura grandiosa, acelerando o processo de relação entre os pares, expandindo o alcance social e modificando principalmente a qualidade desses relacionamentos $(\mathrm{RICH}, 2013)$.

\section{Metodologia}

Utilizou-se como metodologia de pesquisa uma revisão sistemática dos estudos presentes na base de dados Biblioteca Virtual em Saúde (BVS). A revisão sistemática, bem como demais tipos de revisões, consiste em uma forma de pesquisa que se utiliza da bibliografia como objeto de estudo sobre determinado tema. Nesse modo de se investigar um tema, realiza-se um resumo das evidências relacionadas a uma estratégia de intervenção específica, por meio de métodos sistematizados de busca, avaliando de forma crítica e sintetizada as informações. As revisões sistemáticas são eficazes principalmente para reunir as informações de estudos realizados separadamente sobre determinado tema, que podem apresentar resultados que coincidem ou não, assim como identificar temas que necessitam de evidências e, posteriormente, de um maior número de estudos (SAMPAIO; MANCINI, 2006 apud FIGUEREDO et al., 2014). 
A INFLUÊNCIA DA INTERNET NOS ADOLESCENTES COM AÇÕES SUICIDAS

Esse tipo de estudo é identificado, ainda, como meta-analítico, ou seja, como a análise da análise. Sendo assim, para analisar, é preciso haver uma série de estudos já publicados ou disponibilizados bibliograficamente sobre o tema que se quer pesquisar, o que faz com que, consequentemente, a qualidade de uma revisão sistemática dependa da sua fonte primária. Sampaio e Mancini (2006 apud FIGUEREDO et al., 2014) destacam seis fases que caracterizam o processo de construção do trabalho sistemático: construção de protocolo e questões norteadoras; busca de estudos na base de dados; coleta de dados e categorização dos estudos; avaliação crítica dos estudos; interpretação dos resultados; e síntese dos dados, fases essas que foram utilizadas como norteadoras deste estudo.

Foram utilizados os seguintes termos para pesquisa dos artigos publicados: "adolescência", "ideações suicidas" e "internet". Posteriormente, conforme a necessidade, foram colocadas combinações diferentes de duas das três palavras-chaves ou, ainda, combinações de novas palavras-chaves incluídas na grande maioria dos artigos já encontrados. Dessa forma, a lista final de combinações feitas incluiu os seguintes termos: "adolescentes e internet", "suicídio e adolescente", "ideação suicida" e "adolescência e riscos".

Para a busca, consideraram-se os artigos publicados entre 2011 e 2016, escritos em português. Dessa primeira coleta, foram encontrados 90 trabalhos condizentes com a busca.

Considerando o foco em materiais com análise de dados direcionados à ideação suicida em adolescentes e a influência da internet, foram excluídos estudos que se direcionavam a outro grupo específico ou a outra faixa etária, assim como estudos que focassem especificamente jogos on-line e pornografia. Dessa filtragem, restaram 17 artigos, que foram tabelados de forma sistemática, para que os resumos pudessem ser submetidos aos seguintes critérios de inclusão: 1) conter dados empíricos; 2) explorar aspectos influenciáveis da internet em adolescentes; 3) abordar a ideação suicida em adolescentes; e 4) trazer dados conectores entre internet e ideação suicida.

Após essa nova análise, mais 15 artigos foram excluídos: um por não atender a nenhum dos quatro critérios, um por ser repetido, sete por não atenderem aos critérios 2 e 4; um por não atender aos critérios 1, 2 e 4; três por não atenderem aos critérios 2, 3 e 4; e dois por não atenderem aos critérios 3 e 4. Restaram, assim, dois artigos, que atenderam a todos os critérios aplicados aos resumos. Em seguida, esses dois artigos foram revisados e lidos na íntegra, passando, então, à análise.

\section{Resultados}

Os artigos selecionados para análise foram: "Agressão entre pares no espaço virtual: definições, impactos e desafios do cyberbullying", escrito por Guilherme Welter Wendt e Carolina Saraiva de Macedo Lisboa, pertencentes 
ao Curso de Pós-Graduação em Psicologia da Pontifícia Universidade Católica do Rio Grande do Sul (PUC-RS) no ano de 2013; e "Análise do conteúdo de sites que abordam o suicídio", da autoria de Tatiana Gonçalves Ribeiro do Valle e Maria Júlia Kovács, pertencentes ao Instituto de Psicologia Universitária da Universidade de São Paulo (USP), publicado em 2014.

A partir de uma análise mais aprofundada dos dois artigos, foi possível constatar que conteúdos sobre o suicídio na internet estão cada vez mais ligados ao público adolescente, justamente por esse público ser considerado nativo digital, isto é, por possuir mais tempo e mais conhecimento sobre as ferramentas on-line. É por meio da internet que adolescentes praticam e são vítimas de agressões e/ ou exposições, que são fortes causas de isolamento social e depressão, ou ainda buscam informações sobre a prática do suicídio ou ajuda emocional nos momentos de ideação suicida como tentativa de sair desse quadro.

\section{Discussão}

A conexão entre internet e ideação suicida - "Agressão entre pares no espaço virtual: definições, impactos e desafios do cyberbullying"

Por meio de ferramentas de busca na internet, é possível constatar, segundo o material encontrado nos artigos analisados, uma gama de termos ou pesquisas contendo relação com o tema suicídio escritas por pessoas que tentaram se suicidar. $O$ destaque nessas informações reside justamente nos métodos de suicídio, que incluem encorajamento, facilitação e promoção, havendo uma pequena parcela nesse universo de sites que desencorajava, proibia ou prevenia o ato suicida. Tal parcela ressalta que, quando o assunto é a busca de conteúdos abordando suicídio, o Brasil desponta como líder nos países da América Latina.

Os sites revisados nos resultados da presente pesquisa trazem em seus conteúdos desde relatos autobiográficos dos desenvolvedores até informações de prevenção ao suicídio. Em um dos sites, verificam-se algumas informações muito individuais - incentivando a vida e oferecendo alternativas próprias, orientações de como se manter vivo ou de como encontrar saídas, ênfase nas modificações fisiológicas e no uso de medicamentos -, que supostamente serviriam como orientação para quem acessa a plataforma em busca de ajuda. Em outro site, há uma equipe multiprofissional informando e desencorajando o suicídio, sem, entretanto, citar fontes nem deixar explícitos os fundadores, evidenciando, assim, um tom imperativo na intenção de promover a vida, bem como a ênfase em fatores genéticos e associados a psicopatologias na explicação da depressão e do suicídio. No terceiro site analisado, uma equipe de profissionais da área da saúde e legislação manifesta-se, possibilitando ao leitor que ele adquira subsídios para fazer o reconhecimento de seus sintomas e procurar ajuda médica, psiquiátrica e psicológica.

O que chama atenção nesses sites é a maneira como as informações são passadas versus o número de pessoas que têm acesso a elas. São informações 
A INFLUÊNCIA DA INTERNET NOS ADOLESCENTES COM AÇÕES SUICIDAS

com pouca ou nenhuma relevância científica e sem eficácia comprovada em uma amostragem de pessoas. Os relatos de experiências vividas podem não ser entendidos da mesma forma por todos os leitores que buscam por ajuda na internet. O mesmo acontece com as informações e orientações que não contêm a fonte em que se fundamentam. Surge, diante disso, uma preocupação de que o tom imperativo e a proximidade com o conteúdo biográfico ganhem mais evidência do que a própria intenção humanitária de ajudar, e tudo isso ocorre na disseminação em massa, potencializada e multidirecionada, conforme proposta por Castells (2010). Para o autor, por meio dessa rede integrada, as pessoas buscam na coletividade a superação de seus medos, de modo que, mesmo havendo motivações individuais, elas se unem e encontram pontos centrais para exercitar a superação. Tendo em vista o conteúdo desses sites, é bastante sério o fato de que tais informações estejam difusas com material cientificamente empobrecido ou pouco eficiente nos casos de ideação suicida no que concerne à prevenção e a informações para quem busca assistência na internet.

Por outro lado, o que se torna eficaz são as manifestações de agressão por meio do cyberbullying. É muito fácil ocultar e evitar a relação face a face quando se é perpetrador de uma situação de agressão. Na condição de vítima ou praticante, a frequência de ideação suicida é muito maior do que em adolescentes que não têm exposição a qualquer forma de agressão. $O$ estudo analisado aponta, ainda, que $25 \%$ das vítimas de cyberbullying não procuram atendimento especializado, casos em que existe a possibilidade de prejuízos extremos e irreversíveis, como suicídio e homicídios. É possível supor, ainda, conforme prevê Rich (2013 apud ABREU; EISENSTEIN; ESTEFENON, 2014), que a mesma internet, ferramenta de mídia e de pesquisa para diversos temas, é também um meio de exposição dos jovens a conteúdos impróprios e ameaçadores.

A ideação suicida em adolescentes - "Análise do conteúdo de sites que abordam o suicídio"

A ideação suicida é presente em adolescentes, em uma perspectiva ainda que vaga, na elaboração de questões sobre a morte.O artigo resultante da pesquisa aponta que o risco de suicídio é influenciado por fatores diversos, que compreendem, dentre outros, alterações drásticas em um momento inesperado. Entram em cena, nesse caso, os fatores de risco e proteção aos quais o sujeito está exposto; quando os fatores de risco são mais acentuados que os de proteção, ele tende a pensar na morte como solução de suas adversidades. Ainda sobre fatores de proteção, ressalta-se que adolescentes tendem a procurar família ou amigos para conversar e que $69 \%$ dos que cometeram suicídio, segundo a pesquisa, tiveram algum tipo de contato com especialistas em saúde mental no último mês, embora fossem menos propensos a procurar ajuda profissional, preferindo grupos familiares e círculos de amigos para buscar seus fatores de proteção.

O que fica perceptível acerca das características das vítimas de agressões oriundas de ideações suicidas na internet é que são crianças e adolescentes 
frágeis, com poucos recursos de autoproteção ou enfrentamento, que se deparam com conteúdos contendo linguagem depreciativa, conotação sexual, ameaça e ódio. O ciberespaço está, assim, cada vez mais caracterizado como um espaço em que a capacidade de se colocar no lugar do outro fica diminuída.

Essas manifestações extremamente agressivas e intimidadores descritas pelos autores vão ao encontro das informações de Rodriguez e Damásio (2013 apud HABIZANG et al., 2014) e de Zappe e Dell'Aglio (2016) sobre o processo de adolescer, principalmente quanto aos aspectos de pertencimento e formação da autoimagem que se constituem justamente em um processo de desprendimento da supervisão e da identificação dos pais e passam para outros objetos, principalmente amigos, ídolos ou ideologias. Com seus medos e inseguranças, ficam vulneráveis a riscos ou sentimentos de desesperança quando tais pontos de transição e segurança lhes faltam.

No período da adolescência, questões existenciais buscam ser explicadas por meio de uma coerência no modo de vida. Essa incompreensão de identidade vai se resolvendo à medida que a coerência ocorre e que perguntas acerca de quem se é e para que se está no mundo são respondidas. No entanto, quando tais respostas vêm de forma negativa, as questões existenciais ficam muito ligadas a essa agressividade e rejeição, sendo muito fácil para o adolescente não aceitar a si mesmo e acreditar estar no mundo apenas para atrapalhar ou ser rejeitado.

\subsection{Influências da internet em adolescentes}

O termo "nativo digital" é comum aos psicólogos e demais cientistas das áreas mental e social quando se referem à geração conectada às mídias digitais e aos computadores, iniciada por volta dos anos 80. A exposição dos adolescentes em fóruns, blogs, salas de bate papo e redes sociais é cada vez maior, e a interação desses jovens e adolescentes nessa rede de exposição e compartilhamento de informações só faz crescer a demanda dessas plataformas, como confirmam os dois artigos analisados nesta pesquisa.

O tempo gasto conectado à internet está intimamente ligado com os perigos de exposição ao cyberbullying, e, à medida que o jovem interage virtualmente, passa mais tempo utilizando celulares ou computadores de forma individual longe de qualquer supervisão dos pais, ficando, por consequência, mais experiente no assunto, o que torna o processo mais complexo.

Ambos os artigos encontrados inferem que adolescentes vítimas de agressores que se ocultam no mundo on-line apresentam traços de depressão e ansiedade. Os ambientes virtuais possibilitam comunicações anônimas, bem como a experimentação de diversos papéis, fantasias, desejos e angústias, já que o contexto do ciberespaço permite a isenção do contato social puro.

Adolescentes em busca da autonomia assumem a sua identidade no mundo dos adultos e tomam para si referências e itens de sua necessidade, tais como roupas, marcas, personalidades do cinema ou da música, dentre outras 
A INFLUÊNCIA DA INTERNET NOS ADOLESCENTES COM AÇÕES SUICIDAS

características que denotam pertencimento a uma forma de ser ou estar, ainda que isso não esteja explicitamente delimitado. Além disso, como demonstra Rich (2013), nessa aura de pertencimento a um grupo ou a uma moda, existe um facilitador de relações - as redes sociais e a internet. Nelas, as relações tornamse muito fáceis, rápidas e superficiais, de modo que os relacionamentos são acelerados e comprometidos em qualidade. Por fim, ressalta-se que rs estudos analisados nesta pesquisa apontam uma faixa etária de 15 a 24 anos como principal público que busca na internet compartilhamento de informações sobre suicídio.

\section{Conclusão}

As mudanças globais na comunicação e no modo de se relacionar são uma das consequências da expansão das mídias digitais. A internet e suas facilidades causam mudanças nos processos humanos, afetando a qualidade das relações estabelecidas e a maneira de trabalhar, bem como aproximando e facilitando tudo o que o homem já julgou de acesso pouco facilitado. A internet e as mídias estão, dessa forma, mudando até mesmo o ciclo vital do sujeito: não se entra mais na adolescência da mesma forma, tendo em vista os aspectos sexuais e de autoexposição envolvidos no uso da internet.

Nesse sentido, o conflito com a autoimagem, o luto pelo corpo, a instabilidade afetiva e a diferença no modo como percebem suas vidas, comparado a seus pais, são características do mutável processo de adolescer que figuram como combustíveis para que o sujeito busque na internet as inovações no modo de se expressar e se encontrar, seja dentro de um grupo, de um ideal ou de uma perspectiva.

Sentimentos de desesperança, depressão e ideação suicida podem surgir associados a fatores sociais externos ou internos (tais como fatores fisiológicos de ordem hormonal ou psicológicos) quando seus círculos sociais e sua rede de apoio estão desfalcados. É nesse momento que a internet atua como uma janela para outro mundo, onde as informações surgem de todos os lados, sem filtro qualitativo, e são facilmente tomadas como verdades por esses adolescentes. As informações sobre suicídio, seja por meio de sugestões sobre formas de praticar ou sobre prevenção, estão alarmantemente presentes nas buscas on-line dos brasileiros. Somada ao processo crescente do cyberbullying, essa modalidade de agressão e exposição criminosa pela internet serve de alerta para educadores, pesquisadores e especialistas da área da saúde e educação.

A desesperança e o isolamento social do adolescente suicida podem ser confundidos pelos pais e educadores como condutas normais do adolescente, estigmatizado como problemático e sedento de privacidade. Nem sempre, contudo, a privacidade é saudável, uma vez que o computador pode apresentar conteúdos impróprios e os amigos podem não ser realmente o que dizem ser. 
Como foi possível acompanhar pela presente pesquisa, os conteúdos sobre suicídio na internet possuem vertentes distintas: o cyberbullying, que faz vítimas em alvos fáceis, adolescentes frágeis, com pouca capacidade de gerir conflitos; o conteúdo informativo sobre práticas suicidas, facilitando e incentivando os internautas e grupos específicos envolvidos com o tema; e uma corrente que promove a vida e previne o ato suicida por meio de troca de informações, relatos pessoais de superação, instruções e orientações sobre medicamentos, ajuda médica ou religiosa, elementos que, em primeira hipótese, serviriam como pontos positivos de auxílio ao público com ideação suicida.

No entanto, o que chama atenção é a qualidade desses sites, que se destinam à "prevenção à vida", uma vez que apenas um terço possui fontes confiáveis, com orientações dadas por especialistas que oferecem opções de busca por ajuda profissional, dados científicos da Organização Mundial de Saúde (OMS) e outros dados embasados em conteúdo literário coerente e fidedigno. O mesmo não ocorre com o restante dos sites, que apresenta conteúdo autobiográfico, incentivador do autodiagnóstico, imperativo e associado à religião ou a outros veículos, que não se caracterizam como eficazes para uma amostragem considerável de internautas que buscam esse serviço.

Ressalta-se, ainda, a necessidade de mais produções científicas, uma vez que se encontra atualmente um número muito reduzido de artigos e construções no meio acadêmico sobre o tema, o que torna o banco de dados acerca das relações entre a temática suicida em adolescentes e a internet um tanto desatualizado e restrito. Diante disso, fica a proposta de um trabalho aplicado referente ao tema, que permita verificar quantitativa e qualitativamente esse grupo específico de adolescentes frágeis, vulneráveis e suscetíveis a agressores que buscam informações na internet. Outro ponto a ser explorado nesse contexto e que não foi contemplado inteiramente neste artigo é o perfil psicológico predisposto ao suicídio desses adolescentes, bem como demais aspectos que atuam na prevenção da ação suicida nessa faixa etária.

Em suma, quando se trata de informações sobre a temática, existe uma preocupante corrente incentivadora ao suicídio versus outra pouco eficaz em combatê-lo. Os adolescentes apresentam-se como o público em maior contato com o mundo da internet, encontrando-se, muitas vezes, vulneráveis emocionalmente e figurando, consequentemente, como alvos fáceis para a prática da agressão virtual e de conteúdos impróprios sobre a depredação e autoaniquilação, elementos atuantes para que o adolescente suicida não seja impedido ou até mesmo estimulado a cumprir seu objetivo irreversível. 
A INFLUÊNCIA DA INTERNET NOS ADOLESCENTES COM AÇÕES SUICIDAS

\section{Referências}

ABERASTYRY, A e cols. Adolescência. 6 ed. Porto Alegre: Artes Médicas, 1990.

ABERASTURY, A \& KNOBEL, M. Adolescência Normal. 10 ed. Porto Alegre: Artes Médicas, 1992.

ABREU, C.N.; EISENSTEIN, E.; ESTEFENON, S.G. Vivendo esse mundo digital: impactos na saúde, na educação e nos comportamentos sociais. Porto Alegre: Artes Médicas; 2013. p. 35.e 131.

AZEVEDO, A. K ; DUTRA E. S. A Relação amorosa e tentativa de suicídio na adolescência: uma questão de (des)amor. Revista da Abordagem Gestáltica, v.18, n.1, p. 20-29, jan-jun 2012.

BARKLEY, R. A. Seu adolescente desafiador: 10 passos para resolver conflitos e reconstruir seu relacionamento. Porto Alegre: Artmed, 2016. p. 59-61.

BORGES, V. R. \& WERLANG, B. S. G.Estudo de ideação suicida em adolescentes de 15 a 19 anos . Estudos de Psicologia, v. 11, n. 3, p. 345-351, 2006.

BOTEGA, N. J. Crise Suicida: Avaliação e manejo. Porto Alegre: Artmed, 2015. p.135-147.

BRAGA, L. L. Exposição à violência e comportamentos suicidas em adolescentes de diferentes contextos. Tese (Mestrado em Psicologia) - Universidade Federal do Rio Grande do Sul, Porto Alegre, 2011.

BRAGA, L. L.; DELL'AGLIO, D. D. Suicídio na adolescência: fatores de risco, depressão e gênero. Contextos Clínic, São Leopoldo, v. 6, n. 1, p. 2-14, jun. 2013.

BRASIL. Estatuto da criança e do adolescente (1990). Diário Oficial da União. Lei n 8.069, de 13 de Julho de 1990. Brasília, DF

CARVALHO, V.; SALDANHA, H. Suicídio na adolescência: Uma Visão da Psicanálise. Psicologado, maio 2014. Disponível em: <https://psicologado.com/psicopatologia/saude-mental/o-suicidio-na-adolescencia-umavisao-da-psicanalise>. Acesso em: 14 jan. 2015.

CASTELLS, M. Redes de indignação e esperança: movimentos sociais na era da internet. 1ed. Rio de Janeiro. Zahar, 2013.

CONSELHO FEDERAL DE PSICOLOGIA O Suicídio e os Desafios para a Psicologia. Brasília: CFP, 2013.

GOMES, J. O.; BAPTISTA, M. N.; CARNEIRO, A. M. \& CARDOSO, H. F. Suicídio e Internet: Análise de resultados em ferramentas de buscas. Revista Psicologia e Sociedade, v. 21, n. 1, p. 63-73, 2014.

HABIGZANG, L. F.; DINIZ, E.; KOLLER, S. H. Trabalhando com adolescentes: Teoria e Intervenção psicológica. Porto Alegre: Artmed, 2014.

KUCZYNSKI, E. Suicídio na infância e adolescência. Psicologia USP, v. 25, n. 3, p. 246-252, 2014.

MOREIRA, L. C. O. \& BASTOS, P. R. H. O. Prevalência e fatores associados à ideação suicida na adolescência: revisão de literatura. Psicologia Escolar e Educacional, v. 19, n. 3, p. 445-453, 2015.

SILVA, M. R.; FIGUEREDO, M. L. F.; MENDES, W. C. Revisão Sistemática: um caminho para evidências na produção científica de enfermagem. Revista Saúde em Foco, Teresina, v. 1, n. 1, p. 72-81, jan. / jul. 2014. Disponível em http://www4.fsanet.com.br/revista/index.php/saudeemfoco/article/view/333. Acesso em: set. 2016.

SOUSA, M. C. \& MOREIRA, M. I. C. Adolescência em Camadas Populares: Particularidade e Singularidade na Trama Escolar. Revista Pesquisas e Práticas Psicossociais, v. 7, n. 1, São João del-Rei, jan.- jun. 2012.

WAISELFISZ, J. J. Mapa da Violência 2014: os jovens do Brasil. Brasília, 2014. Disponível em: http://www. mapadaviolencia.org.br/pdf2014/Mapa2014_JovensBrasil_Preliminar.pdf Acesso em 17 abr. 2015.

WENDT, G. W. \& LISBOA, C. S. Agressão entre pares no espaço virtual: definições, impactos e desafios do cyberbullying. Psic. Clin., Rio de Janeiro, v. 25, p.73-87, 2013.

WORLD HEALTH ORGANIZATION (WHO). Participant manual - Preventing Suicide: A Global imperative. 2014. Disponível em: http://apps.who.int/iris/bitstream/10665/131056/1/9789241564779_eng.pdf. Acesso em: 16 abr. 2015. 
VALLE, T. G. R. \& KOVÁCS, M. J. Análise do conteúdo de sites que abordam suicídio. Boletim de Psicologia, São Paulo, n. 140, 2014.

VERMELHO, S. C. et al. Refletindo sobre as redes sociais digitais. Educ. Soc., Campinas, v. 35, n. 126, p. 179-196, mar. 2014. Disponível em: <http://www.scielo.br/scielo.php?script=sci_arttext\&pid=S010173302014000100011\&lng=en\&nrm=iso>. Acesso em: 13 maio 2015.

VIOLA, D. T. D., \& VORCARO, A. M. R. O problema do saber na adolescência e o real da puberdade. Psicologia USP, v. 26, n. 1, p. 62-70, 2015.

ZAPPE, J. G. \& DELL'AGLIO, D. D. (2016). Variáveis pessoais e contextuais associadas a comportamentos de risco em adolescentes. Jornal Brasileiro de Psiquiatria, v. 65, n. 1, p. 44-52, 2016. 